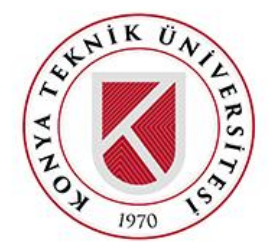

Konya Mühendislik Bilimleri Dergisi, c. 9, Özel Sayı, 10-16, 2021

Konya Journal of Engineering Sciences, v. 9, Special Issue, 10-16, 2021

ISSN: 2667-8055 (Elektronik)

DOI: $10.36306 /$ konjes.972477

\title{
ZnO KONSANTRASYONUNUN ORGANIK GÜNEŞ HÜCRELERINDE VERIME ETKİSİ
}

\author{
1Semih YURTDAŞ (iD) , 2 Mustafa KARAMAN (iD) , ${ }^{3}$ Cem TOZLU \\ ${ }^{1}$ Karamanoğlu Mehmetbey Üniversitesi, Mühendislik Fakültesi, Enerji Sistemler Mühendisliği Bölümü, Karaman, \\ TÜRKIYYE \\ ${ }^{2}$ Konya Teknik Üniversitesi, Mühendislik ve Doğa Bilimleri Fakültesi, Kimya Mühendisliği Bölümü, Konya, \\ TÜRKIYY \\ ṡ̇zmir Katip Çelebi Üniversitesi, Mühendislik ve Mimarlık Fakültesi, Malzeme Bilimi Mühendisliği Bölümü, \\ İzmir, TÜRKIYE \\ ${ }^{1}$ syurtdas@kmu.edu.tr; ${ }^{2}$ mkaraman@ktun.edu.tr, ${ }^{3}$ cem.tozlu@ikcu.edu.tr
}

ÖZ: Bu çalışmada, sol-jel yöntemi ile sentezlenmiş ZnO molaritesinin P3HT (Poli (3-hekzil tiyofen)):PCBM $((6,6)$ Fenil-C61-Bütirik asit metil ester) aktif tabakalı güneş hücresinde verime olan etkisi incelenmiş ve $0,1,0,3$ ve $0,5 \mathrm{M}$ değerlerinde çalışılmıştır. Aygıtların verim değerleri, $100 \mathrm{mw} / \mathrm{cm}^{2}$ güneş 1şıması altında Keithley 2400 kaynak ölçer cihazı yardımı ile belirlenmiştir. Ayrıca XRD, UV-Vis ve FESEM teknikleri ile karakterizasyon işlemleri gerçekleştirilmiştir. Yapılan çalışmalar sonrasında $0,1 \quad M$ sentez konsantrasyonunun, en uygun koşul olduğu bulunmuş ve bu şartlarda üretilen aygit ile \%3,09 verime ulaşılabildiği tespit edilmiştir.

Anahtar Kelimeler: ZnO, Elektron taşıyıcı tabaka, Polimer güneş hücreleri

\section{Effect of ZnO Concentration on Efficiency in Organic Solar Cells}

\begin{abstract}
In this study, the effect of the molarity of ZnO synthesized by the sol-gel method on the efficiency of P3HT (Poly (3-hexyl thiophene)):PCBM $((6,6)$ Phenyl-C61-Butyric acid methyl ester) active layer solar cell was investigated. It was studied at $0.1,0.3$ and $0.5 \mathrm{M}$ values. The efficiency values of the devices were determined with the Keithley 2400 source meter under $100 \mathrm{mw} / \mathrm{cm}^{2}$ solar radiation. In addition, characterization processes were carried out with XRD, UV-Vis and FESEM techniques. After the studies, it was found that $0.1 \mathrm{M}$ synthesis concentration was the most suitable condition and it was determined that $3.09 \%$ efficiency could be reached with the device produced under these conditions.
\end{abstract}

Keywords: $\mathrm{ZnO}$, Electron transport layer, Polymer solar cells

\section{GİRIŞ̧ (INTRODUCTION)}

Konjuge polimerler ve fulleren türevlerinin bileşiminden oluşan polimer güneş hücreleri, yenilenebilir enerji kaynağı olarak büyük ilgi çekmektedirler (Sun ve diğ., 2011). Bunun nedenleri ucuz olmaları, düşük sıcaklık proseslerine uygun olmaları (Zhu ve diğ., 2014), hafif olmaları (Ma ve diğ., 2015), esnek yüzeylere uygulanabilirlikleri ve kolay üretilebilmeleri (Xia ve diğ., 2015) şeklinde sıralanabilir. Bu güneş hücreleri temel olarak katot, elektron taşıyıcı tabaka (ETT), aktif tabaka, boşluk taşıyıcı tabaka (BTT) ve anottan oluşur. ETT ve BTT kullanılmasının başlıca sebebi serbest yük taşıyıcılarının (elektron ve boşlukların) kontaklardan daha verimli bir şekilde toplanmasını sağlamaktır.

Aygitı oluşturan tabakaların enerji seviyelerinin birbiri ile uyumu dikkat edilmesi gereken bir noktadır. Aksi takdirde yük taşıyıcılarının rekombinasyonu gerçekleşebilir (Ragoussi ve Torres, 2015). Burada dikkat edilmesi gereken nokta üst elektrotun iş fonksiyonu donör malzemenin HOMO'sundan 
(highest occupied molecular orbital energy level; işgal edilmiş en yüksek moleküler orbital enerji seviyesi) yeterince yüksek olmalı; alt elektorun iş fonksiyonu akseptör malzemenin LUMO'sundan (Lowest unoccupied molecular orbital energy level; işgal edilmemiş en düşük moleküler orbital enerji seviyesi) düşük olmalıdır. Ayrıca enerji seviyelerinin iyi eşleşebilmesi için evrik yapılarda alt elektrotun üzerine bir ETT; üst elektrotun altına da bir BTT ince bir şekilde kaplanır (Lattante, 2014).

ETT olarak ZnO (Guan ve diğ., 2016; Lin ve ark., 2017; Gui ve diğ., 2018; Zafar ve ark., 2019; Fanady ve ark., 2020) ve $\mathrm{TiO}_{2}$ (Docampo ve diğ., 2013; Wang ve diğ., 2017; Li ve diğ., 2018; $\mathrm{Lv}$ ve diğ., 2019; Afzali ve diğ., 2020) en sık kullanılan materyallerdir. ZnO'in yüksek elektron hareketliliği, çevreyle dost olması, yüksek optiksel geçirgenliği ve aktif tabaka ile ohmik kontak oluşturması onu iyi bir ETT yapar (Wei ve diğ., 2013).

ZnO CVD (Biswas ve diğ., 2016), ALD (Hoye ve diğ., 2013), sol-jel (Liang ve diğ., 2012), nanokristal (Pacholski ve diğ., 2002) ve çözelti prosesi (Lin ve diğ., 2014) gibi pek çok yöntemle sentezlenebilir. CVD ve ALD yöntemlerinde pahalı ekipmanlara ihtiyaç vardır. Sol-jel, nanokristal ve çözelti prosesi yöntemleri ise nispeten daha ucuzdur. Grubumuz tarafından yapılan bir çalışmada (Yurtdaş ve diğ., 2021) bu üç yöntemin polimer güneş hücrelerinde kullanımı karşılaştırılmıştır. Bulduğumuz sonuçlara göre en uygun yöntem sol-jel yöntemidir. Bu çalışmanın amacı ise sol-jel yöntemi ile $\mathrm{ZnO}$ sentezinde optimum $\mathrm{ZnO}$ konsantrasyonunun belirlenmesidir.

\section{MATERYAL VE YÖNTEM (MATERIALS AND METHOD)}

\section{Materyaller (Materials)}

Kullanılan kimyasallar hiçbir saflaştırma işlemine tabi tutulmamıştır. Güneş hücresinde alttaş olarak

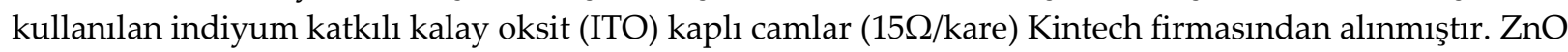
sentezinde kullanılan $\mathrm{Zn}\left(\mathrm{CH}_{3} \mathrm{COO}\right)_{2} .2 \mathrm{H}_{2} \mathrm{O}$ (\%98-101) ve 2-Metoksietanol Alfa Aesar, etanolamin $(\% 99,5)$ ise Aldrich firmasından temin edilmiştir. Üretilen güneş hücresinin aktif tabakasını oluşturan poli(3hekziltiofen-2,5-diil) (P3HT) (\%93) ve (6,6)-fenil C61 bütirik asit metil ester (PCBM) (\%99,5) Lum-Tech., klorobenzen (\%100) ise VWR firmasından sağlanmıştır. Güneş hücresinin BTT'sini oluşturan $\mathrm{MoO}_{3}$ $(\% 99,8)$ Sigma-Aldrich, üst kontağı olan Ag $(\% 99,9)$ ise Alfa Aesar firmasından temin edilmiştir.

\section{ZnO Sentezi (Synthesis of ZnO)}

Sol-jel yöntemi ile sentezlenen $\mathrm{ZnO}$ için Liang ve arkadaşlarının (2012) önerdikleri yöntem kullanılmıştır. Öncelikle çinko asetat dihidrat, 2-metoksi etanol içerisine eklenir ve sıcaklık ile beraber karıştırma uygulanır. Bir süre sonra mono etanol amin (MEA) eklenir. MEA ve çinko asetat dihidrat molar oranlarının 1:1 olmasına dikkat edilir. $60^{\circ} \mathrm{C}$ sıcaklıkta 2 sa karıştırıldıktan sonra reaksiyon sonlandırılır ve 1 gün yaşlanmaya bırakılır.

\section{Aygit Üretimi (Manufacture of Device)}

Arzu edilen konsantrasyonda sentezlenen $\mathrm{ZnO}$ çözeltisi, dönel kaplama cihazı yardımı ile istenilen hızda ITO yüzeyi üzerine kaplanmıştır. Kaplandıktan sonra $150{ }^{\circ} \mathrm{C}$ sıcaklıkta tavlama işlemine tabi tutulmuştur. Tavlama işlemi sonrasında 1:1 (P3HT:PCBM) oranında klorobenzen içerisinde hazırlanan aktif tabaka ZnO üzerine dönel kaplama cihazı yardımı ile kaplanmıştır. Aktif tabaka kaplama işlemi inert atmosfer sağlayan eldivenli kabin (glovebox) içerisinde gerçekleştirilmiştir. Aktif tabaka kaplandıktan sonra $120^{\circ} \mathrm{C}$ sıcaklıkta $25 \mathrm{dk}$ boyunca tavlanmıştır. Son olarak BTT $\left(\mathrm{MoO}_{3}\right)$ ve anodun (Ag) kaplanması için filmler fiziksel buhar biriktirme (PVD) cihazına alınmıştır. Sistem $10^{-6}$ torr basınca düştükten sonra 8 nm kalınlığında $\mathrm{MoO}_{3}$ ve yaklaşık $80 \mathrm{~nm}$ kalınlığında Ag kaplanarak aygıt üretimi tamamlanmıştır. Aygıt yapım sürecinin şematik gösterimi Şekil 1'de verilmiştir. 

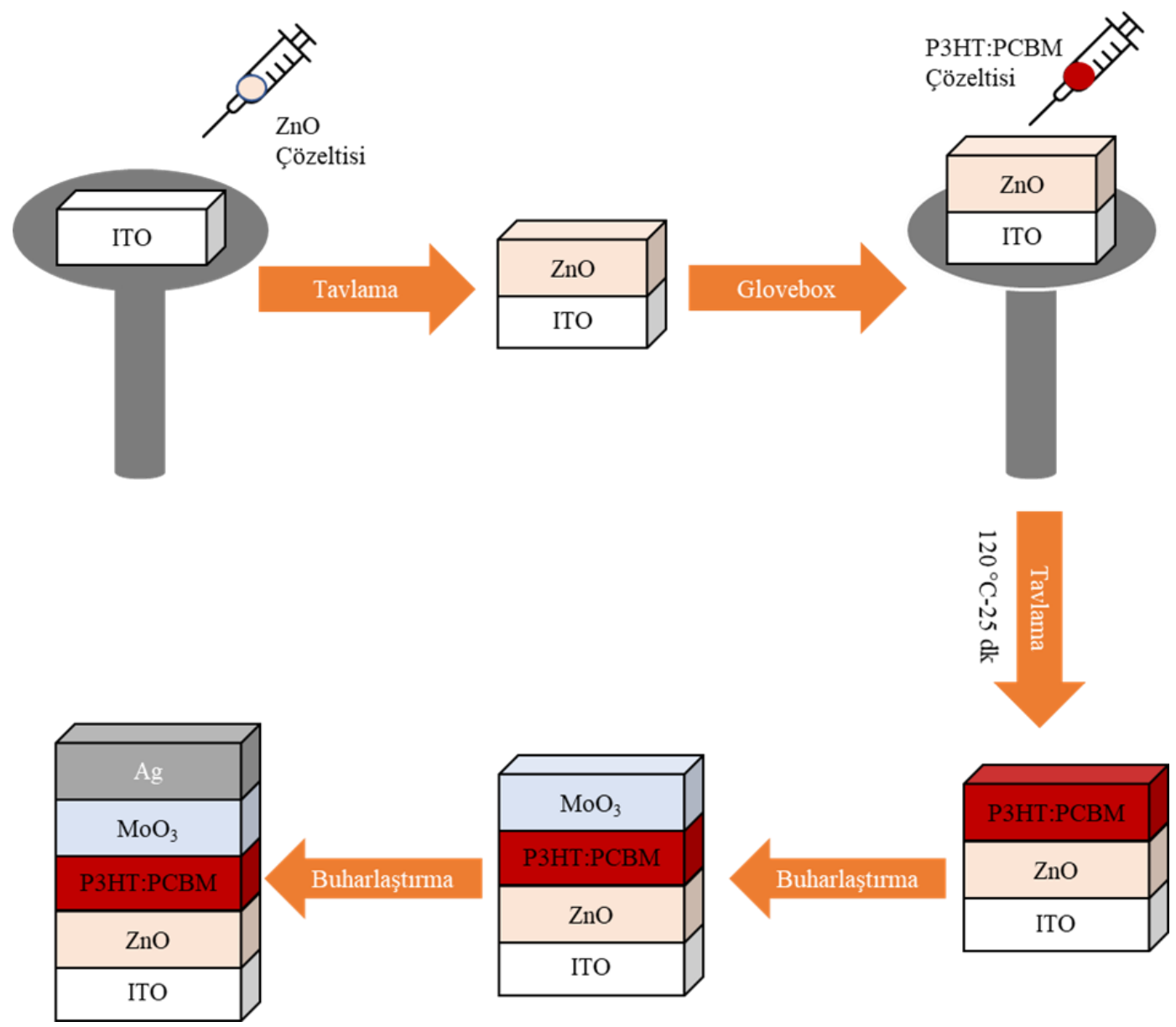

Şekil 1. Aygıtların üretiminin şematik gösterimi

Figure 1. Shematic representation of the manufacture of devices

\section{Karakterizasyonlar (Characterizations)}

$\mathrm{ZnO}$ sentezi yapılıp ince film halinde kaplamalar yapıldıktan sonra kristallenme sıcaklığı hakkında bilgi edinmek amacıyla XRD analizi yapılmıştır. Analizler Rigaku Ultima-IV cihazı ile gerçekleştirilmiş olup 0,2 grazing açısı kullanılmıştır. Hazırlanan ZnO çözeltilerinin UV-Vis spektrofotometre (Hach DR5000) analizi ile geçirgenliği belirlenmiştir. ZnO kaplı ince filmlerin yüzey morfolojisini incelemek için ise FESEM (Alan Emisyonlu Taramalı Elektron Mikroskopu) (Hitachi SU-5000) analizi gerçekleştirilmiştir. FESEM analizi yapılmadan önce filmlerin iletkenliğini sağlamak için Au/Pd ile Ar gazı akışı altında saçtırma tekniği ile Leica EM ACE200N cihazında kaplama yapılmıştır. Üretilen güneş hücrelerinin verimleri; $100 \mathrm{~mW} / \mathrm{cm}^{2}$, A.M 1,5 G ve oda sıcaklığı koşullarında glovebox içerisinde ölçülmüştür. $1000 \mathrm{~W}$ OAI Marka Trisol Sınıf AAA güneş simülatörü ve Keithley 2400 kaynak ölçer cihazları kullanılarak aygıtların elektriksel karakterizasyonları gerçekleştirilmiştir.

\section{ARAŞTIRMA BULGULARI (RESULTS)}

Şekil 2 incelendiğinde $\mathrm{ZnO}$ ince filmlerinin $150^{\circ} \mathrm{C}^{\prime}$ de kristallenmeye başladığı görülmektedir. ZnO'ler ince film şeklinde cam üzerine büyütüldüğünden $20-30^{\circ}$ arasındaki geniş pik alt taş olan cama aittir. Diğer piklerin ise sirasiyla 31,8, 34,4, 36,3, 47,5, 56,6, 62,9 ve 68 derecelerinde pik veren 00-36-1451 pdf kart numarasına sahip hekzagonal kristal yapısındaki $\mathrm{ZnO}^{\prime}$ e ait olduğu belirlenmiştir. Bu piklere karşılık gelen hkl indisleri sırasiyla 100, 002, 101, 102, 110, 103, 112 şeklindedir. 


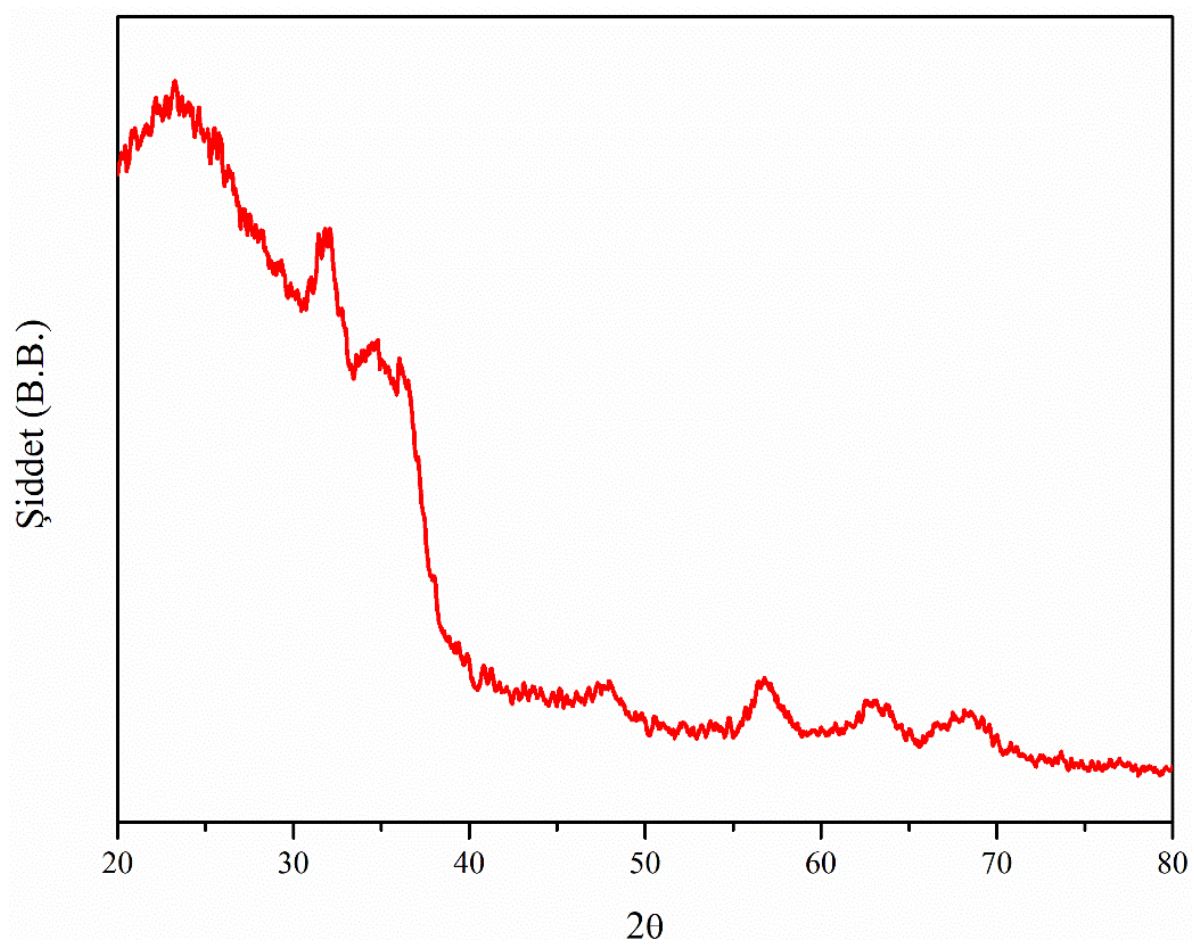

Şekil 2. ZnO ince filminin XRD deseni

Figure 2. XRD pattern of $\mathrm{ZnO}$ thin film

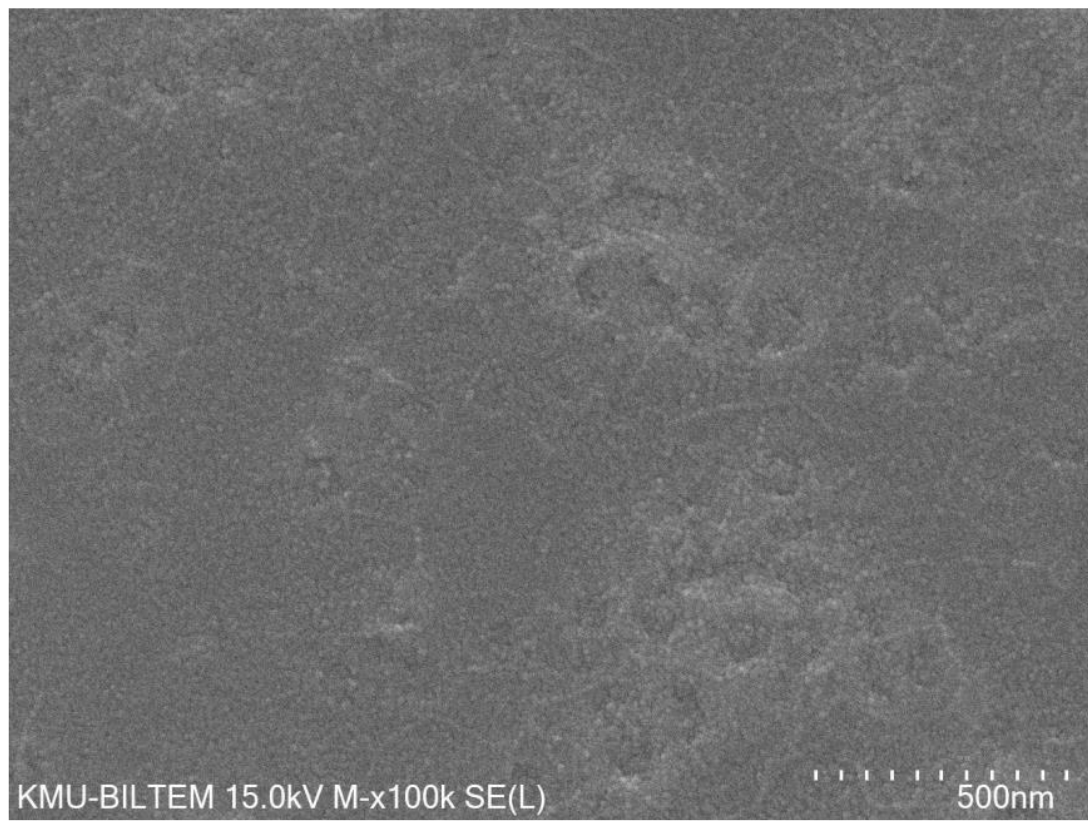

Şekil 3. ZnO kaplı ince filmin FESEM görüntüsü

Figure 3. FESEM images of $\mathrm{ZnO}$ thin film

Şekil 3 incelendiğinde görüleceği üzere tüm yüzey oldukça homojen bir şekilde kaplanabilmiştir. Elde edilen $\mathrm{ZnO}$ taneciklerinin boyutunun yaklaşık olarak $13 \mathrm{~nm}$ olduğu imageJ programı yardımı ile tespit edilmiştir.

$150{ }^{\circ} \mathrm{C}$ tavlama sıcaklığında $\mathrm{ZnO}$ yapısının oluştuğu ve kaplanan filmlerin morfolojisinin oldukça düzgün olduğu belirlendikten sonra $\mathrm{ZnO}$ konsantrasyonu üzerinde çalışılmıştır. Polimer güneş hücrelerinde sentezlenen ETT'nin konsantrasyonu önemli bir parametredir. Çalışmada 0,1-0,3-0,5 M konsantrasyonlarında $\mathrm{ZnO}$ sentezlenmiş ve bu sentezlerle aygıtlar yapılmıştır. Sonuçlar Çizelge 1 ve Şekil 
3'te verilmiştir. Çizelge 3'te yer alan ortalama sonuçlar dötr hücrenin ortalaması alınarak belirlenmiştir. Şekil 4'te yer alan J-V grafikleri ise en iyi hücrelerin sonuçlarından oluşmaktadır.

Çizelge 3. ZnO konsantrasyonunun aygitların elektriksel parametrelerine etkisi Table 3. Effect of $\mathrm{ZnO}$ concentration on electrical parameters of devices

\begin{tabular}{|c|c|c|c|c|c|c|c|c|}
\hline \multirow{2}{*}{$\begin{array}{l}\text { Molarite } \\
\text { (M) }\end{array}$} & \multicolumn{4}{|c|}{ En İyi Sonuçlar } & \multicolumn{4}{|c|}{ Ortalama Sonuçlar } \\
\hline & $\mathrm{J}_{\mathrm{sc}}\left(\mathrm{mA} / \mathrm{cm}^{2}\right)$ & $\mathrm{V}_{\text {oc }}(\mathrm{mV})$ & FF (\%) & $\eta(\%)$ & $\mathrm{J}_{\mathrm{sc}}\left(\mathrm{mA} / \mathrm{cm}^{2}\right)$ & $\mathrm{V}_{\text {oc }}(\mathrm{mV})$ & FF $(\%)$ & $\eta(\%)$ \\
\hline 0,1 & 7,66 & 590 & 68,3 & 3,09 & 7,73 & 590 & 66 & 3,01 \\
\hline 0,3 & 7,50 & 590 & 68,4 & 3,03 & 7,41 & 592,5 & 66,8 & 2,93 \\
\hline 0,5 & 7,05 & 600 & 66,8 & 2,83 & 7,10 & 597,5 & 64,3 & 2,72 \\
\hline
\end{tabular}

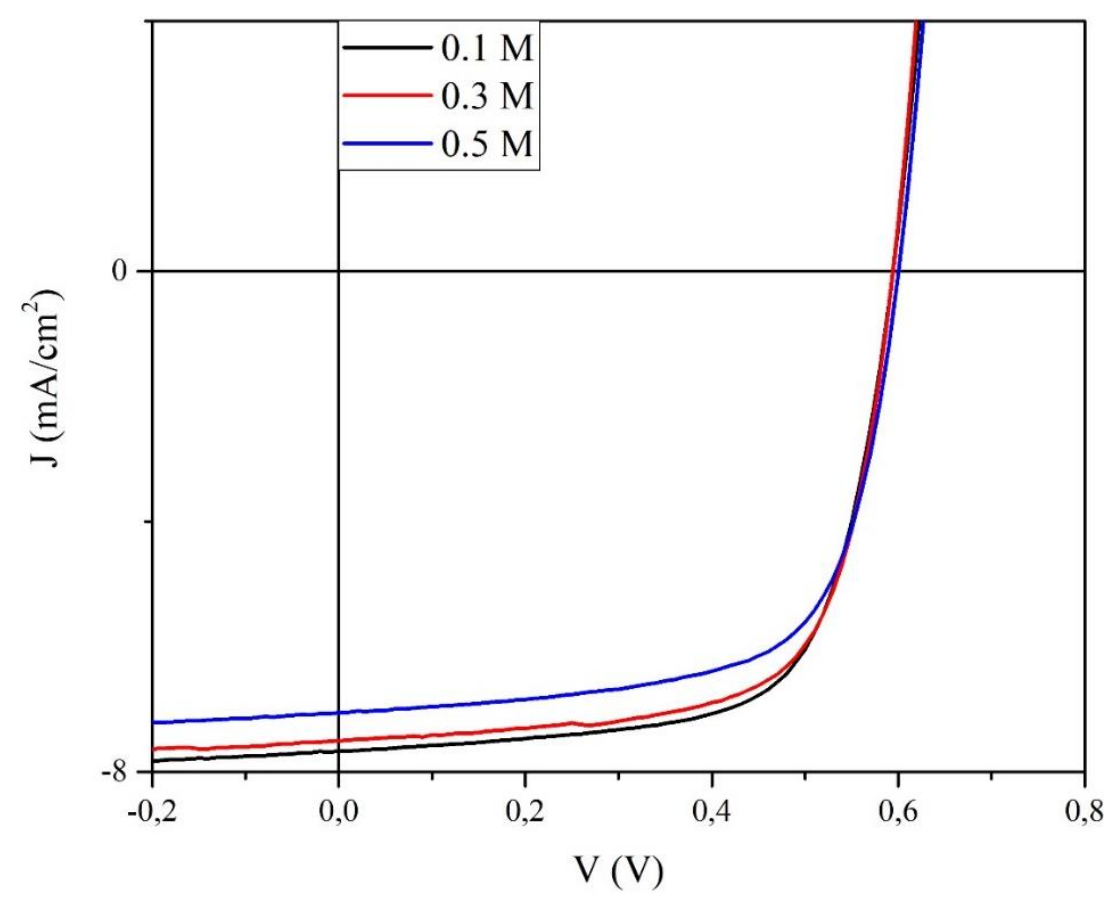

Şekil 4. ZnO konsantrasyonunun aygit verimi üzerine etkisi Figure 4. Effect of $\mathrm{ZnO}$ concentration on device efficiency

Sonuçlar incelendiğinde $\mathrm{ZnO}$ konsantrasyonu arttıkça verimin azaldığı görülmektedir. Verimi azaltan parametrenin ise akım yoğunluğu olduğu belirlenmiştir. Akım yoğunluğunun azalması aktif tabakaya ulaşan foton miktarının azalması veya kontaklardan toplanan serbest yük taşıyıcı miktarının azalması ile gerçekleşebilir. Şekil 5'te farklı konsntrasyonlardaki ZnO'lerin UV-Vis sonuçları verilmiştir. Sonuçlar konsantrasyon arttıkça geçirgenliğin azaldığını, bunun da aygıt içerisinde aktif tabakaya ulaşan foton miktarının azalmasına yol aç九tğını göstermektedir. 


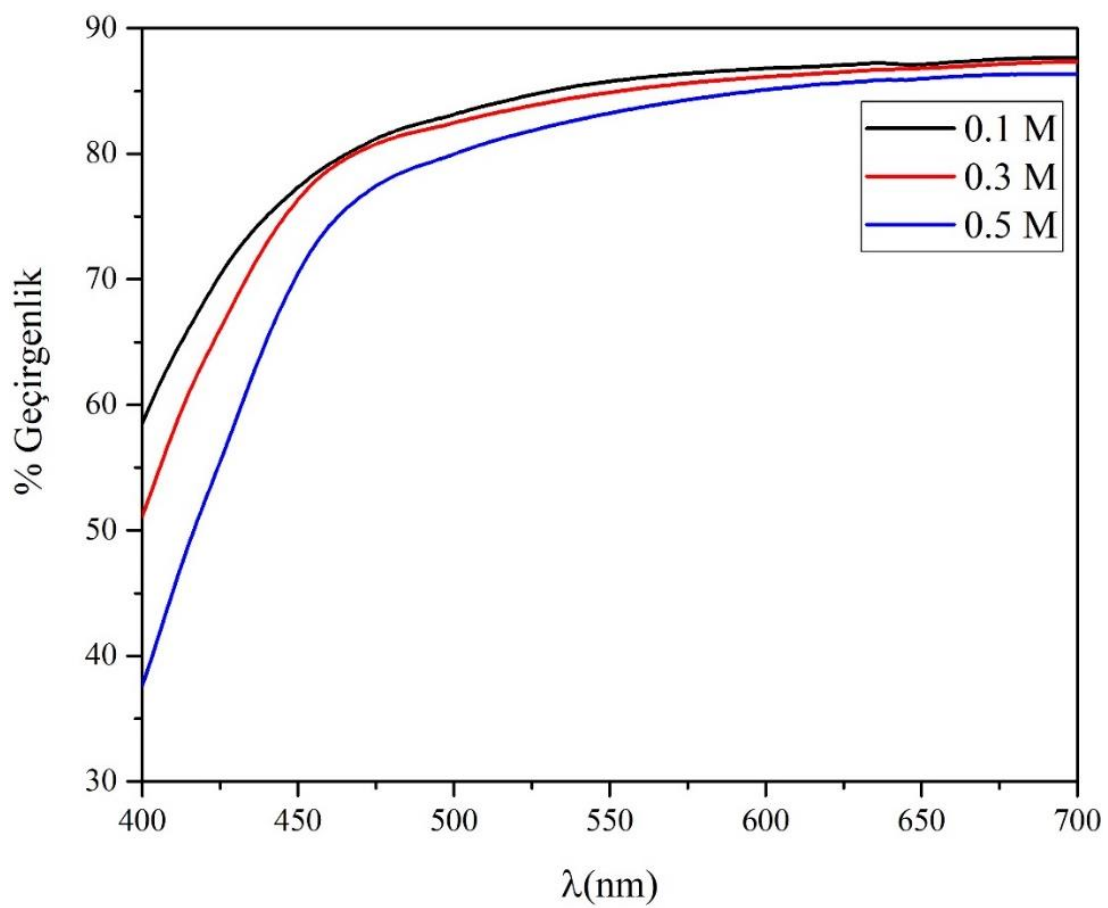

Şekil 5. Farklı konsantrasyonlarda sentezlenen ZnO'lerin UV-Vis sonuçları Figure 5. UV-Vis results of ZnO's synthesized at different concentrations

\section{SONUÇ ve TARTIŞMALAR (RESULTS and DISCUSSIONS)}

Verimli bir aygıt yapmak için güneş hücresini oluşturan tüm katmanlar çok önemlidir. Gerek sahip olduğu enerji seviyelerinin aktif tabaka ve ITO ile olan uyumu gerekse iyi optiksel ve elektriksel özellikleri ile $\mathrm{ZnO}$ ideal bir ETT'dir. Bu çalışmada sol-jel yöntemi ile sentezlenmiş olan $\mathrm{ZnO}$ konsantrasyonunun aygıt verimi üzerindeki etkisi incelenmiştir. Hazırlanan $\mathrm{ZnO}$ çözeltisinin konsantrasyonunun geçirgenliği ve dolayısıyla akım yoğunluğunu etkilediği, en yüksek verime 0,1 M konsantrasyon ile ulaşıldığ1 görülmüştür. Ortalama değerler incelendiğinde 0,1 M konsantrasyon ile yapılan aygitlar ile 0,3 $\mathrm{M}^{\prime}$ a göre yaklaşı \% $\% 5^{\prime}$ lik bir akım yoğunluğu (Jsc) ve \%3'lük verim $(\eta)$ artışı olduğu görülmektedir. 0,5 M'a göre ise bu artış miktarları akım yoğunluğu ve verim için sırasıyla \%9 ve \%11 şeklinde olduğu belirlenmiştir.

\section{KAYNAKLAR (REFERENCES)}

Afzali, M., Mostafavi, A., Shamspur, T., 2020, "Performance enhancement of perovskite solar cells by rhenium doping in nano-TiO, compact layer", Organic Electronics, 86, 105907.

Biswas, C., Ma, Z., Zhu, X., Kawaharamura, T., Wang, K. L., 2016, “Atmospheric growth of hybrid ZnO thin films for inverted polymer solar cells", Solar Energy Materials \&Solar Cells Cells (Sol. Energ. Mater. Sol. C.), 157, 1048-1056.

Docampo, P., Ball, J. M., Darwich, M., Eperon, G. E., Snaith, H. J., 2013, “Efficient organometal trihalide perovskite planar-heterojunction solar cells on flexible polymer substrates", Nature Communications (Nat. Commun), 4, 2761, 1-6.

Fanady, B., Song, W., Peng, R., Wu, T., Ge, Z., 2020, “Efficiency enhancement of organic solar cells enabled by interface engineering of sol-gel zinc oxide with an oxadiazole-based material", Organic Electronics, 76, 105483.

Guan, H., Xu, W., Li, X., Peng, H., Feng, Y., Zhang, J., Li, C., 2016, “Implementation of photo thermal annealing on $\mathrm{ZnO}$ electron transporting layer for high performance inverted polymer solar cells", Materials Letters, 163, 69-71. 
Gui, Z. Z., Liu, X. H., Ming, S. Q., Zhang, J., Y., Xie, Q. M., Chen, T., Wang, H. Q., 2018, “Efficient organic solar cells employing ytterbium ion-doped zinc oxide as cathode transporting layer", Organic Electronics, 53, 296-302.

Hoye, R. L. Z., Munoz-Rojas, D., Iza, D. C., Musselman, K., P., MacManus-Driscoll, J. L., 2013, “High performance inverted bulk heterojunction solar cells by incorporation of dense, thin $\mathrm{ZnO}$ layers made using atmospheric atomic layer deposition", Solar Energy Materials \& Solar Cells (Sol. Energ. Mater. Sol. C.), 116, 197-202.

Lattante, S., 2014, "Electron and hole transport layers: Their use in inverted bulk heterojunction polymer solar cells", Electronics, 3, 1, 132-164.

Li, S., Zhu, X., Wang, B., Qiao, Y., Liu, W., Yang, H., Liu, N., Chen, M., Lu, H., Yang, Y., 2018, “Influence of Ag Nanoparticles with Different Sizes and Concentrations Embedded in a $\mathrm{TiO}_{2} \mathrm{Compact}$ Layer on the Conversion Efficiency of Perovskite Solar Cells", Nanoscale Research Letters, 13, 210, 1-11.

Liang, Z., Zhang, Q., Wiranwetchayan, O., Xi, J., Yang, Z., Park, K., Li, C., Cao, G., 2012, “Effects of the Morphology of a ZnO Buffer Layer on the Photovoltaic Performance of Inverted Polymer Solar Cells", Advanced Functional Materials (Adv. Funct. Mater.), 22, 10, 2194-2201.

Lin, C. C., Tsai, S. K., Chang, M. Y., 2017, “Spontaneous growth by sol-gel process of low temperature ZnO as cathode buffer layer in flexible inverted organic solar cells", Organic Electronics, 43, 218-225.

Lin, Z., Chang, J., Jiang, C., Zhang, J., Wu, J., Zhu, C., 2014, “Enhanced inverted organic solar cell performance by post-treatments of solution-processed $\mathrm{ZnO}$ buffer layers", RSC Advances, 4, 6646-6651.

Ma, Z. S., Wang, Q. K., Li, C., Li, Y. Q., Zhang, D. D., Liu, W., Wang, P., Tang, J. T., 2015, “Efficient inverted polymer solar cells integrated with a compound electron extraction layer", Optics Communications, 356, 541-545.

Pacholski, C., Kornowski, A., Weller, H., 2002, "Self-Assembly of ZnO: From Nanodots to Nanorods", Angewandte Chemie International Edition (Angew. Chem. Int. Ed.), 41, 7, 1188-1191.

Ragoussi, M. E. ve Torres, T., 2015, "New generation solar cells: concepts, trends and perspectives", Chemical Communications (ChemComm), 51, 3957-3972.

Sun, Y., Seo, J. H., Takacs, C. J., Seifter J., Heeger, A., 2011, “Inverted Polymer Solar Cells Integrated with a Low-Temperature-Annealed Sol-Gel-Derived ZnO Film as an Electron Transport Layer", Advanced Materials (Adv. Mater.), 23, 1679-1683.

Wang, X., Zhang, Z., Qin, J., Shi, W., Liu, Y., Gao, H., Mao, Y., 2017, “Enhanced Photovoltaic Performance of Perovskite Solar Cells Based on Er-Yb Co-doped $\mathrm{TiO}_{2}$ Nanorod Arrays", Electrochimica Acta, 245, 839-845.

Wei, W., Zhang, C., Chen, D., Wang, Z., Zhu, C., Zhang, J., Lu, X., Hao, Y., 2013, “Efficient “Light-soaking”free Inverted Organic Solar Cells with Aqueous Solution Processed Low-Temperature ZnO Electron Extraction Layers", ACS Applied Materials \& Interfaces (ACS Appl. Mater. Interfaces), 5, 13318-13324.

Xia, X., Bian, Z., Huang, C., 2015, “Overcoming the thickness paradox: Systematical optimization of inverted polymer solar cells", Current Applied Physics, 15, 1364-1369.

Zafar, M, Yun, J. Y., Kim, D. H., 2019, “Improved inverted-organic-solar-cell performance via sulfur doping of $\mathrm{ZnO}$ films as electron buffer layer", Materials Science in Semiconductor Processing, 96, 66-72.

Zhu, Y., Yuan, Z., Cui, W., Wu, Z., Sun, Q., Wang, S., Kang, Z., Sun, B., 2014, “A cost-effective commercial soluble oxide cluster for highly efficient and stable organic solar cells", Journal of Materials Chemistry A, (J. Mater. Chem. A), 2, 1436-1442. 